\title{
Evaluation of Clinical and Radiological Outcomes of Subvastus and Medial Parapatellar Approaches in Total Knee Arthroplasty
}

\section{Total Diz Artroplastisinde Subvastus ve Medial Parapatellar Yaklaşımın Klinik ve Radyolojik Sonuçlarının Değerlendirilmesi}

\author{
Necati Emirhan ${ }^{1 \oplus}$, Furkan Yapici ${ }^{2}$ \\ ${ }^{1}$ Balikesir Gönen State Hospital \\ ${ }^{2}$ Department of Orthopedics and Traumatology, Erzincan University Faculty of Medicine
}

Received: 11.05.2020 / Accepted: 05.01.2021 / Published Online: 31.03.2021

Cite as: Emirhan N, Yapici F. Evaluation of clinical and radiological outcomes of subvastus and medial parapatellar approaches in total knee arthroplasty. Med J Bakirkoy 2021;17(1):18-24.

\begin{abstract}
Objective: The aim of this study is to compare clinically and radiologically the subvatus (SV) and medial parapatellar (MPP) approaches performed in patients undergoing total knee arthroplasty (TKA) due to severe gonarthrosis.

Method: Patients who underwent TKA between 2015 and 2019 were divided into two groups as SV and MPP, according to the type of approach performed. Demographic, clinical, and surgical information of the patients were evaluated. Knee Society Clinical Rating System (KSS) and visual analogue scale (VAS) scores were used for functional evaluation. AP and lateral orthoroentgenograms and knee radiographs taken at the last follow-up were used for radiological evaluation.

Results: The mean duration of surgery and tourniquet was significantly higher in the SV group. $(p<.001$ and $p<.001$, respectively). Mean blood loss and number of blood transfusions were significantly higher in the MPP group. ( $p<.001$ and $p<.001$, respectively). Opiate analgesic need, straight leg raising time and hospitalization time were also significantly higher in the MPP group. $(p<.001, p<.001$ and $p<.001$, respectively). Although the KSS, VAS scores, and the range of motion (ROM) at the first month were better in the SV group, there was no difference between the two groups at 6 and 12 months.

Conclusion: According to this study, with the SV approach used for TKA, postoperative blood loss and the need for transfusion decreased, the duration of hospitalization was shortened, postoperative pain was less, and functional scores were better. Its only disadvantage was the prolonged operation time.
\end{abstract}

Keywords: TKA, Total Knee Arthroplasty, Approach, Subvastus Approach, Parapatellar Approach.

öz

Amaç: Bu çalışmanın amacı, ileri evre gonartroz nedeniyle total diz artroplastisi (TDA) uygulanan hastalarda kullanılan subvatus (SV) ve medial parapatellar (MPP) girişimlerin klinik ve radyolojik olarak karşılaştırılmasıdır.

Yöntem: 2015-2019 yılları arasında TDA uygulanan hastalar kullanılan girișim tipine göre SV ve MPP grubu olarak ikiye ayrıldı. Hastaların demografik, klinik ve ameliyat bilgileri incelendi. Fonksiyonel değerlendirme için Knee Society Clinical Rating System (KSS) ve visual analogue scale (VAS) skorları kullanıldı. Radyolojik değerlendirme için son kontrolde çekilen AP ve lateral bacak uzunluk grafisi ve diz grafileri kullanıldı. Bulgular: Bu çalışmaya göre, TDA için kullanılan SV girişim ile ameliyat sonrası kan kaybının ve transfüzyon ihtiyacının azaldığı, hastanede yatış süresinin kısaldığı, ameliyat sonrası ağrının daha az olduğu ve fonksiyonel skorların daha iyi olduğu görülmüştür. Tek dezavantajı ameliyat süresinin uzamasıdır.

Sonuç: SV grubundaki ortalama ameliyat ve turnike süresi anlamlı olarak yüksekti. ( $p<.001$ ve $p<.001$, sırasılyla). MPP grubunda ise ortalama kan kaybı ve kan transfüzyonu sayısı anlamlı olarak yüksekti. ( $p<.001$ ve $p<.001$, sırasıyla). Opiyat analjezik ihtiyacı, düz bacak kaldırma süresi ve yatış süresi de MPP grubunda anlamlı olarak yüksekti. ( $p<.001, p<.001$ ve $p<.001$, sırasıyla). Birinc aydaki KSS ve VAS skorları ile eklem hareket açıklı̆ı SV grubunda daha iyi olmasına rağmen 6. ve 12. ayda iki grup arasında fark yoktu.

Anahtar Kelimeler: TDA, Total Diz Artroplastisi, Girişim, Subvastus Girişim, Parapatellar Girişim. 


\section{INTRODUCTION}

Knee osteoarthritis (gonarthrosis) is a common disease in older-aged individuals that decreases their quality of life by causing pain and functional limitations. Total knee arthroplasty (TKA) is a successful treatment option in older patients whose symptoms are not relieved with conservative management ${ }^{(1)}$. The frequency of performing the TKA procedure is increasing in correlation with the increase in the life span and the development of implant technologies ${ }^{(2)}$. It is essential to perform a suitable technique in an appropriate patient to achieve higher satisfaction after the TKA procedure ${ }^{(3)}$. The standard arthrotomy techniques commonly used in TKA are the anterior medial (medial parapatellar), subvastus, midvastus, and anterior lateral (lateral parapatellar) approaches. The medial parapatellar arthrotomy is the most commonly used approach with the advantage of good exposure, but with the disadvantages of disrupting the extensor mechanism and patellar blood supply ${ }^{(4,5)}$.

The subvastus approach has been described by Erkes in 1929 and its importance was recognized in the literature by Hoffman in $1991{ }^{(6)}$. Hoffman et al. remarked that this approach preserves the integrity of the extensor mechanism and maintains the vascular supply to the patella ${ }^{(7)}$. Despite the difficulty in obtaining good surgical exposure, the subvastus approach has been reported as a favorable technique with better early rehabilitation compared with the medial parapatellar approach ${ }^{(8)}$. In addition to that, preservation of the patellar blood supply, avoidance of patellar maltracking, and improved rehabilitation are the most remarkable advantages of the subvastus approach ${ }^{(9-11)}$. However, the subvastus approach is not a commonly used technique in the TKA procedure ${ }^{(12)}$. Besides, there is still a lack of a high level of evidence in the literature about the superiority of the subvastus approach over the medial parapatellar approach ${ }^{(13)}$.

In our center, we performed the subvastus approach routinely and observed better patient-reported outcomes regarding the return to normal daily activities compared with the medial parapatellar approach. Therefore, the aim of the current study was to evaluate and compare the clinical and radiological outcomes of subvastus and medial parapatellar approaches in patients who underwent TKA for severe gonarthrosis.
We hypothesized that the subvastus approach would have better clinical outcomes in the early postoperative period compared with the parapatellar approach. However, we also hypothesized that patients' clinical outcomes would be similar during follow-ups.

\section{MATERIALS and METHODS}

\section{Study Population}

This retrospective study was performed under the approval of the institutional ethical review board and conducted in accordance with the principles of Declaration of Helsinki. The clinical and radiographical data of patients who underwent TKA between 2015 and 2019 were reviewed from our medical records. Patients aged between 50 and 80 years with a diagnosis of Kellgren-Lawrence stage 4 primary osteoarthritis, who underwent primary TKA were included in the study. The patients with a history of operation, lower extremity fracture, inflammatory arthritis, incomplete medical record, and those lost to follow-up were excluded from the study. The data of 134 patients were evaluated in this study. Patients were grouped according to the type of approach for TKA. The choice of approach was time-dependent. The senior surgeon who routinely did the operations performed the medial parapatellar approach in patients who were admitted between 2015 and 2017 (MPP group), whereas another senior surgeon started to perform the subvastus approach after 2017 (SV group). Patients' age, gender, body mass index, American Society of Anesthesiologists (ASA) score were recorded from our medical records.

\section{Surgical Technique}

All surgeries were performed by two senior orthopedic surgeons under either general or regional anesthesia. A pneumatic tourniquet was applied to the thigh in all patients and set at a pressure of $300 \mathrm{~mm} \mathrm{Hg}$. All surgeries were performed through a midline skin incision. In the SV group, the subvastus approach was performed as described previously in the literature ${ }^{(7)}$. In the MPP group, the procedure was performed classically, as introduced by Insall (14,15). A posterior stabilizing knee prosthesis (Vanguard ${ }^{\circledR}$, Zimmer Biomet, IN, USA) was used for each patient. Any patellar surface component was not used for any patient. The skin incision was closed after release of the tourniquet, and bleeding was controlled. A suction 
drain was placed in all patients and removed on the postoperative first day. All patients received a firstgeneration cephalosporin for 24 hours and lowmolecular-weight heparin for four weeks postoperatively. Perioperative blood loss was at a neglegible level due to tourniquet use. Postoperative blood loss $(\mathrm{mL})$ was measured from suction drainage. Patients' preoperative and postoperative hemoglobin levels $(\mathrm{mg} / \mathrm{dL})$ were recorded from medical records. The total erythrocyte transfusion was indicated if the hemoglobin level was below $8 \mathrm{mg} / \mathrm{dL}$ and/or tachycardia was present. The number of total erythrocyte transfusions was also recorded.

\section{Postoperative Rehabilitation}

Patients were mobilized on the first postoperative day and weight-bearing was allowed. Isometric and isokinetic knee exercises were started on the first postoperative day. The need for opiate analgesics (number of doses), straight leg raise time (day), time to walk independently with assistance (day), and total hospitalization time (day) were recorded for each patient.

\section{Data Collection}

The functional outcome was evaluated by the Knee Society Clinical Rating System (KSS) score that was measured preoperatively and in the first and third months. The visual analogue scale (VAS) score was also assessed preoperatively, at hospital discharge, and in the first month postoperatively. The final preoperative and postoperative follow-up range of motion (ROM) of the knee joint was measured for each patient.

The radiographic outcome was assessed through postoperative standing orthoroentgenograms that were taken at the last follow-up visit. The femoral and tibial varus/valgus alignments were measured on the anteroposterior (AP) radiographs. The femoral and tibial alignments were also measured on the lateral radiographs. All images were evaluated by two independent reviewers who were blinded to the follow-up time after the surgical intervention. The correlation coefficient between the reviewers was 0.90. All complications were recorded.

\section{Statistical Analysis}

Statistical analysis was performed using SPSS 25.0 (SPSS Inc., IBM, NY, USA). Numerical variables are given as means and standard deviations, and categorical variables are provided as frequencies and percents. The comparison of means was performed using the Student's t-test, whereas the comparison of frequencies was performed by the chi-square test. A post-hoc power analysis was performed to determine the power of the study. P-values less than .05 were considered statistically significant.

\section{RESULTS}

The demographics of patients are shown in Table 1. No significant differences were observed between groups concerning patients' age, gender, body mass index, and ASA scores. The mean follow-up time was significantly higher in the MPP group compared with the SV group $(p<.001)$ (Table 1$)$.

The clinical and operative characteristics of the study groups are shown in Table 2. The operation time and tourniquet time were significantly higher in the SV group ( $p<.001$ and $p<.001$, respectively). However, the mean postoperative blood loss and the number of transfusions performed were significantly higher in the MPP group ( $p<.001$ and $p<.001$, respectively). The mean preoperative and postoperative hemoglobin levels did not significantly differ between groups $(p=.68$ and $p=$ .07 , respectively). The number of opiate analgesics needed, straight leg raise times, and hospitalization times were also significantly higher in the MPP group ( $p<.001, p<.001$ and $p<.001$, respectively) (Table 2 ).

Functional outcomes are listed in Table 3. In the first postoperative month, KSS pain and function scores were significantly higher in the SV group $(p<.001$ and $p<.001$, respectively). The mean flexion ROM of the knee joint was significantly higher in the SV group $(p<.001)$. However, the mean VAS score did not significantly differ between groups $(p=.4)$. In the third postoperative month, the KSS function score was significantly higher in the SV group $(p<.001)$. However, the means of the other scores and the flexion ROM did not significantly differ between groups. In the sixth and twelfth postoperative months, we did not observe any significant differences between the groups regarding KSS scores, VAS scores, and flexion ROMs.

The radiographic outcomes are presented in Table 4. No significant differences were observed between the groups regarding femoral and tibial alignment 
Table 1. Comparison of demographic data of patients with $p$ values.

\begin{tabular}{|l|c|c|c|}
\hline & SV Group (n=82) & MPP Group (n=52) & p value \\
\hline Age (year) & $65.7 \pm 8.1$ & $66.9 \pm 8.9$ & 0.43 \\
\hline Gender & & & 0.46 \\
\hline Female & 69 & 66 & 0.07 \\
\hline Male & 13 & $27.2 \pm 2$ & 0.28 \\
\hline BMI (kg/m2) & $27.9 \pm 2.2$ & & 10 \\
\hline ASA Score & & & 35 \\
\hline ASA I & 95 & 7 & 0 \\
\hline ASA II & 8 & & \\
\hline ASA III & 0 & & \\
\hline ASA IV & $14.3 \pm 5.5$ & & \\
\hline Follow-up (month) & \multicolumn{2}{|c|}{0} & \\
\hline SV: Subvastus, MPP: Medial parapatellar, BMI: body mass index, ASA: American Society of Anesthesiologists. \\
\hline
\end{tabular}

Table 2. Comparison of clinical and operative characteristics of groups.

\begin{tabular}{|l|c|c|c|}
\hline Variables & SV Group (n=82) & MPP Group (n=52) & p value \\
\hline Operation Time (minute) & $68.4 \pm 10.2$ & $61.1 \pm 10.1$ & $<0.001$ \\
\hline Tourniquet Time (minute) & $45.4 \pm 9.8$ & $38.5 \pm 9.3$ & 0.001 \\
\hline Preoperative Hgb level (mg/dL) & $12.3 \pm 1.6$ & $12.2 \pm 1.3$ & 0.08 \\
\hline Postoperative Hgb level (mg/dL) & $9.7 \pm 1.0$ & $10.1 \pm 1.4$ & $<0.001$ \\
\hline Postoperative Blood Loss (mL) & $486.8 \pm 126.9$ & $570.1 \pm 144.6$ & $<0.001$ \\
\hline Transfusions (n) & $0.2 \pm 0.4$ & $0.5 \pm 0.5$ & $<0.001$ \\
\hline Opiate need & $0.3 \pm 0.4$ & $0.6 \pm 0.6$ & $<0.001$ \\
\hline Straight leg raising time (day) & $1.3 \pm 0.4$ & $2.5 \pm 0.8$ & 0.76 \\
\hline Time to walk with aid (day) & $2.2 \pm 0.4$ & $2.2 \pm 0.4$ & $<0.001$ \\
\hline Hospital stays (day) & $2.3 \pm 0.4$ & $3.7 \pm 0.7$ & \\
\hline \\
SV: subvastus, MPP: medial parapatellar, $\mathrm{n}:$ number, Hgb: \\
Hemoglobin
\end{tabular}

angles measured from the anteroposterior and lateral radiographs (Table 4).

No major complications occurred during the followup. Seven patients in the SV group and five patients in the MPP group had superficial wound infections that resolved with parenteral antibiotic treatment.

\section{DISCUSSION}

The most important findings of this study were the observations of better postoperative clinical outcomes including lower postoperative blood loss, requirement for transfusion, and use of opiate analgesics. Besides, our results demonstrated significantly better early functional outcomes in patients who underwent TKA with the SV approach.

However, functional outcomes became similar in the sixth and twelfth postoperative months. In a recent metaanalysis of randomized controlled trials, Berstock et al. presented evidence of early postoperative benefits following the subvastus approach with comparable outcomes between these approaches in the long term ${ }^{(6)}$.

Hu et al. did not demonstrate a difference between the 
Table 3. Comparison of functional outcomes of groups with $p$ values.

\begin{tabular}{|c|c|c|c|}
\hline & SV Group (n=82) & MPP Group (n=52) & $\mathrm{p}$ value \\
\hline \multicolumn{4}{|l|}{ KSS Pain Score } \\
\hline Preoperative & $30.5 \pm 3.7$ & $31.3 \pm 4.4$ & 0.32 \\
\hline Postoperative 1st month & $82.5 \pm 5.1$ & $78.4 \pm 4.8$ & $<0.001$ \\
\hline Postoperative 3rd month & $88.0 \pm 1.9$ & $87.7 \pm 1.7$ & 0.3 \\
\hline Postoperative 6th month & $89.7 \pm 3.4$ & $89.1 \pm 3.9$ & 0.4 \\
\hline Postoperative 12th month & $90.8 \pm 2.5$ & $89.8 \pm 2.4$ & 0.07 \\
\hline \multicolumn{4}{|l|}{ KSS Function Score } \\
\hline Preoperative & $48.7 \pm 5.0$ & $47.5 \pm 4.3$ & 0.12 \\
\hline Postoperative 1st month & $81.9 \pm 5.5$ & $78.5 \pm 6.1$ & $<0.001$ \\
\hline Postoperative 3rd month & $86.5 \pm 4.7$ & $83.7 \pm 5.0$ & $<0.001$ \\
\hline Postoperative 6th month & $87.5 \pm 4.1$ & $86 \pm 5.1$ & 0.07 \\
\hline Postoperative 12th month & $89 \pm 4.7$ & $87.2 \pm 6.2$ & 0.06 \\
\hline \multicolumn{4}{|l|}{ VAS score } \\
\hline Preoperative & $4.7 \pm 0.8$ & $4.8 \pm 1.1$ & 0.4 \\
\hline At discharge & $2.6 \pm 1.1$ & $3.6 \pm 0.9$ & $<0.001$ \\
\hline Postoperative 1st month & $2.1 \pm 1.2$ & $2.3 \pm 1.2$ & 0.4 \\
\hline Postoperative 3rd month & $1.9 \pm 1.2$ & $2.2 \pm 1.3$ & 0.3 \\
\hline Postoperative 6th month & $1.9 \pm 2$ & $2.1 \pm 1.6$ & 0.3 \\
\hline Postoperative 12th month & $1.8 \pm 1.4$ & $2 \pm 1.2$ & 0.8 \\
\hline \multicolumn{4}{|l|}{ Range of motion (degree) } \\
\hline Preoperative & $107.0 \pm 12.4$ & $107.0 \pm 12.5$ & 1.00 \\
\hline Postoperative 1st month & $114.6 \pm 5.4$ & $104.2 \pm 6.6$ & $<0.001$ \\
\hline Postoperative 3rd month & $114.1 \pm 5.4$ & $112.6 \pm 12$ & 0.41 \\
\hline Postoperative 6th month & $116.8 \pm 6.2$ & $114.4 \pm 12.8$ & 0.21 \\
\hline Postoperative 12th month & $117.3 \pm 6.8$ & $114.8 \pm 9.3$ & 0.14 \\
\hline
\end{tabular}

SV and the MPP approaches concerning the operation time and intraoperative blood loss ${ }^{(13)}$. Boerger et al. reported less blood loss, but longer operation and tourniquet times with the SV approach ${ }^{(16)}$. In their metaanalysis of the randomized controlled trials, Peng et al. mentioned that the operation time was longer with the SV approach ${ }^{(17)}$. However, the authors did not report any difference between the SV and the MPP approaches regarding blood loss (17). In our study, we observed significantly longer operation and tourniquet times, whereas a significantly lower blood loss in the SV approach. According to the literature and the results obtained from our study, the prolonged operation time because of the limited exposure is a common concern for the SV approach in TKA.

Tomek et al. reported no significant difference between the quadriceps sparing SV technique and the MPP technique regarding opioid analgesic use and early functional outcomes (18). Hu et al. mentioned earlier straight leg raise and superior knee flexion within one week postoperatively ${ }^{(13)}$. Boerger et al. observed that patients who underwent TKA with the SV approach reached 90 degrees knee flexion earlier, and had an active straight leg raise earlier compared with those who underwent TKA with the MPP approach (16). The authors also found lower pain scores and decreased use of analgesics in the SV group ${ }^{(16)}$. Similarly, Berstock et al. also reported that patients who underwent TKA by the SV approach had earlier straight leg raise, decreased pain scores, reduced need for analgesic use, and thus had decreased hospitalization times compared with the MPP approach ${ }^{(6)}$. Our results were also consistent with the literature. Indeed, we detected a significantly earlier straight leg raise, lower opiate analgesic use, shorter hospitalization times, as well as lower VAS scores compared with the MPP group at discharge. According to the literature and our 
Table 4. Comparison of radiographic outcomes of the study groups.

\begin{tabular}{|l|c|c|c|}
\hline & SV Group (n=82) & MPP Group (n=52) & p value \\
\hline Anteroposterior radiographs & & & \\
\hline Femoral valgus alingment & $93.1 \pm 3.6$ & $93.7 \pm 3.9$ & 0.32 \\
\hline Tibial varus alingment & $88.9 \pm 1.5$ & $89.3 \pm 1.6$ & 0.19 \\
\hline Lateral radiographs & & & 0.17 \\
\hline Femoral flexion angle & $5.1 \pm 7.8$ & $6.8 \pm 6.1$ & 0.89 \\
\hline Tibial alingment angle & $88.6 \pm 2.5$ & $88.5 \pm 2.1$ & \\
\hline SV: Subvastus, MPP: medial parapatellar, $n$ :number.
\end{tabular}

results, we might consider that patients who underwent TKA by the SV approach were more comfortable concerning early postoperative pain scores and functional outcomes compared with those who underwent TKA by the MPP approach. Effective pain relief strategies should be used, especially in patients who undergo TKA by the classical MPP approach.

Boerger et al. reported similar functional outcomes based on KSS scores between the SV, and the MPP approaches in TKA; however, the authors found that the early VAS scores were significantly better in the SV group ${ }^{(16)}$. Cila et al. observed similar improvements in the knee scores in the sixth postoperative week, third month, and sixth month in their study that compared the SV and the MPP approaches ${ }^{(19)}$. In their meta-analysis of randomized controlled trials, Berstock et al. found no significant differences between the SV and the MPP approaches in KSS scores ${ }^{(6)}$. However, in another meta-analysis of randomized controlled trials, Peng et al. showed that the SV approach was superior to the MPP approach regarding VAS and KSS scores ${ }^{(17)}$. According to the results obtained from our study, we observed that both the VAS and the KSS scores were significantly better in the SV approach compared with the MPP approach in the first postoperative month. However, functional scores and pain scores were similar in the third, sixth, and twelfth postoperative months. Besides, postoperative knee flexion ROM was significantly better in the SV group in the first postoperative month. Hu et al. also reported better knee ROM in the first postoperative week in their meta-analysis ${ }^{(13)}$. However, the authors did not report a significant difference between the SV and the MPP approaches regarding functional scores ${ }^{(13)}$. Both KSS and VAS are patient-reported subjective scores. Thus, it is challenging to have a better understanding of the differences between the reported studies in the literature. Nevertheless, both results reported in the literature and obtained in our study have ensued in comparable functional knee scores over the long term. On the other hand, better knee ROM in the early postoperative period seems to provide a proven advantage of the SV approach in TKA.

Boerger et al. and Tzatzairis et al. reported similar outcomes in component alignment between the SV and the MPP approaches after TKA ${ }^{(16,20)}$. On the other hand, Chen et al. observed that radiological outcomes were inferior in the SV approach compared with the MPP approach ${ }^{(12)}$. We also saw similar radiological outcomes regarding the femoral and tibial component alignments in our study. The main disadvantage of the SV approach is limited exposure compared with the MPP approach. Thus, the malalignment of the components might be seen when comparing the SV approach with the classic MPP approach with better exposure. However, this surgeon-related disadvantage could be avoided by improving the surgical technique, which has a learning curve, as does the MPP approach.

The complication rates of the SV and the MPP approaches were reviewed from the reported studies. Studies comparing the SV and the MPP approaches mostly reported similar postoperative complication rates $(5,6,12,19,20)$. However, Boerger et al. reported higher complication rates with the SV approach due to the longer operative time ${ }^{(16)}$. Our results were also consistent with the current literature; we observed similar complication rates between our study groups. Postoperative complications might be affected by many different parameters rather than the surgical approaches. Therefore, it is difficult to randomize and control these parameters to determine the complication rates in a clinical study.

The main limitations of our study are its retrospective design and its limited number of patients. However, we reported a prospectively followed patient population who were treated with the same protocol. 
Besides, the choice of the surgical approach was timedependent, and this issue prevented potential patient selection bias. This study is not the first study in the literature comparing the SV and the MPP approaches. Nevertheless, our study showed the main advantages and disadvantages of the SV technique, and we have demonstrated relatively similar outcomes as previously reported studies. Besides, a post-hoc analysis was performed for significant variables, and the minimum statistical power was calculated as 0.93 for the comparison of means $(\alpha=0.05)$.

\section{CONCLUSION}

According to the results of this study, the SV approach to the TKA procedure resulted in longer operative times, decreased postoperative blood loss, reduced need for transfusion, shorter hospitalization times, less early postoperative pain, and better functional scores. The subvastus approach can be performed safely and successfully with the advantage of early postoperative pain relief and improved functional outcomes.

Ethics Committee Approval: Erzincan Binali Yildirim University Clinical Research Ethics Committee (12.02.2019, 38/08).

Conflict of Interest: No conflict of interest was declared by the authors.

Funding: The authors received no financial support for the research, authorship, and/or publication of this article.

Informed Consent: Informed consent was obtained from all participants.

\section{REFERENCES}

1. Younger AS, Duncan CP, Masri BA. Surgical exposures in revision total knee arthroplasty. J Am Acad Orthop Surg. 1998;6(1):55-64 . doi: 10.5435/00124635-199801000-00006.

2. Kurtz S, Ong K, Lau E, Mowat F, Halpern M. Projections of primary and revision hip and knee arthroplasty in the United States from 2005 to 2030. J Bone Joint Surg Am. 2007;89(4):780-5. doi: 10.2106/JBJS.F.00222.

3. Robertsson O, Dunbar M, Pehrsson T, Knutson K, Lidgren L. Patient satisfaction after knee arthroplasty: a report on 27,372 knees operated on between 1981 and 1995 in Sweden. Acta Orthop Scand. 2000;71(3):262-7. doi: 10.1080/000164700317411852.

4. Bourke MG, Buttrum PJ, Fitzpatrick PL, Dalton PA, Jull GA, Russell TG. Systematic review of medial parapatellar and subvastus approaches in total knee arthroplasty. J Arthroplasty. 2010;25(5):728-34. doi: 10.1016/j.arth.2009.06.008.

5. Bourke MG, Jull GA, Buttrum PJ, Fitzpatrick PL, Dalton PA, Russell TG. Comparing outcomes of medial parapatellar and subvastus approaches in total knee arthroplasty: a randomized controlled trial. J Arthroplasty. 2012;27(3):347-53.e1. doi: 10.1016/j.arth.2011.06.005.

6. Berstock JR, Murray JR, Whitehouse MR, Blom AW, Beswick AD. Medial subvastus versus the medial parapatellar approach for total knee replacement: A systematic review and meta-analysis of randomized controlled trials. EFORT Open Rev. 2018;3(3):78-84. doi: 10.1302/2058-5241.3.170030.

7. Hofmann AA, Plaster RL, Murdock LE. Subvastus (Southern) approach for primary total knee arthroplasty. Clin Orthop Relat Res. 1991;(269):70-7. PMID: 1864059.

8. Bridgman SA, Walley G, MacKenzie G, Clement D, Griffiths D, Maffulli N. Sub-vastus approach is more effective than a medial parapatellar approach in primary total knee arthroplasty: a randomized controlled trial. Knee. 2009;16(3):216-22. doi: 10.1016/j.knee.2008.11.012.

9. Kayler DE, Lyttle D. Surgical interruption of patellar blood supply by total knee arthroplasty. Clin Orthop Relat Res 1988;(229):2217. PMID: 3349681.

10. Matsueda M, Gustilo RB. Subvastus and medial parapatellar approaches in total knee arthroplasty. Clin Orthop Relat Res. 2000;(371):161-8. doi: 10.1097/00003086-200002000-00020.

11. Lin TC, Wang HK, Chen JW, Chiu CM, Chou HL, Chang $\mathrm{CH}$. Minimally invasive knee arthroplasty with the subvastus approach allows rapid rehabilitation: a prospective, biomechanical and observational study. J Phys Ther Sci. 2013;25(5):557-62. doi: 10.1589/jpts.25.557.

12. Chen AF, Alan RK, Redziniak DE, Tria AJ Jr. Quadriceps sparing total knee replacement. The initial experience with results at two to four years. J Bone Joint Surg Br. 2006;88(11):1448-53. doi: 10.1302/0301-620X.88B11.18052.

13. Hu X, Wang $G$, Pei F, et al. A meta-analysis of the sub-vastus approach and medial parapatellar approach in total knee arthroplasty. Knee Surg Sports Traumatol Arthrosc. 2013;21(10):2398-404. doi: 10.1007/s00167-012-2080-9.

14. Jhurani A, Agarwal P, Aswal M, Rasquinha C, Srivastava M. Subvastus exposure compared to parapatellar approach in navigated Sequential Bilateral Total Knee Arthroplasty (SBTKA): A prospective randomized study. J Knee Surg. 2019. doi: 10.1055/s-0039-1700496.

15. Insall J. A midline approach to the knee. J Bone Jt Surg Am Ed. 1971;53(8):1584-6. PMID: 5121799.

16. Boerger TO, Aglietti $P$, Mondanelli N, Sensi L. Mini-subvastus versus medial parapatellar approach in total knee arthroplasty. Clin Orthop Relat Res. 2005;440:82-7.

17. Peng $X$, Zhang $X$, Cheng T, Cheng $M$, Wang J. Comparison of the quadriceps-sparing and subvastus approaches versus the standard parapatellar approach in total knee arthroplasty: a meta-analysis of randomized controlled trials. BMC Musculoskelet Disord. 2015;16:327. doi: 10.1186/s12891-015-0783-z.

18. Tomek IM, Kantor SR, Cori LA, et al. Early patient outcomes after primary total knee arthroplasty with Quadriceps-Sparing Subvastus and Medial Parapatellar Techniques: A randomized, double-blind clinical trial. J Bone Joint Surg Am. 2014;96(11):907-15. doi: 10.2106/JBJS.L.01578.

19. Cila E, Güzel V, Ozalay $M$, et al. Subvastus versus medial parapatellar approach in total knee arthroplasty. Arch Orthop Trauma Surg. 2002;122(2):65-8. doi: $10.1007 / \mathrm{s} 004020100319$.

20. Tzatzairis T, Fiska A, Ververidis A, Tilkeridis K, Kazakos K, Drosos $\mathrm{GI}$. Minimally invasive versus conventional approaches in total knee replacement/arthroplasty: A review of the literature. J Orthop. 2018;15(2):459-66. doi: 10.1016/j.jor.2018.03.026. 